\title{
Coupling a global climatic model with insurance impact models for flood and drought: an estimation of the financial impact of climate change
}

\author{
Pierre Tinard ${ }^{1}$, Zi-Xiang Wang ${ }^{1}$, David Moncoulon ${ }^{1, a}$, Martine Veysseire ${ }^{2}$, Fabienne Regimbeau ${ }^{2}$ and Michel Déqué $^{2}$ \\ ${ }^{1}$ CCR, R\&D - Technical Studies Public Reinsurance, 157 bd Haussmann, 75008 Paris, France \\ ${ }^{2}$ Météo-France, 42 av Coriolis, 31057 Toulouse Cedex 1, France
}

\begin{abstract}
CCR, a French reinsurance company mostly involved in natural disasters coverage in France, has been developing tools for the estimation of its exposure to climatic risks for many years. Both a flood and a drought models were developed and calibrated on a large policies and claims database supplied every year with insurers' data. More recently, CCR has been developing a stochastic approach in order to evaluate its financial exposure to extreme events. A large and realistic event set has been generated by applying extreme value statistic tools to simulate hazard and to estimate, using our impact models, the average annual losses and losses related to different return periods. These event sets have been simulated separately for flood and drought, with a hypothesis of independence, consistent with recent annual damage data. The newest development presented here consists in the use of the ARPEGE-Climat model performed by Météo-France to simulate two 200-years sets of hourly atmospheric time series reflecting both the current climate and the RCP 4.5 climate conditions circa year 2050. These climatic data constitute the input data for the flood and drought impact models to detect events and simulate the associated hazard and damages. Our two main goals are (1) to simulate simultaneously flood and drought events for the same simulated years and (2) to evaluate the financial impact of climate change.
\end{abstract}

\section{Context of the study}

Since 1982, in France, the natural disasters and especially those related to climatic events such as flood, drought or cyclonic winds rely on a Natural Catastrophe (Nat Cat) compensation scheme for insured losses. CCR (Caisse Centrale de Réassurance) is a public reinsurer providing an unlimited State-guaranteed coverage to its clients in the case of natural disasters.

The question of climate change is now a central concern in the world. The last report by the Intergovernmental Panel on Climate Change (IPCC) stresses that this change would probably result in an increase in the number of extreme events in the world, such as heat waves or extremely heavy rainfall. Recent extreme events in southern France in the autumns of 2014 and 2015 are perhaps the first signs of this.

As CCR is clearly exposed to the financial consequences of natural disasters occurring in France through the Nat Cat compensation scheme, it has been developing its own impact models: since 2003 for flood [1], 2005 for drought [2] and 2011 for storm surge [3]. These models are designed to fulfil two main objectives:
- to estimate the financial impact of natural events, shortly after their occurrence, for insurance companies, for CCR and for the French state, i.e. the deterministic approach;

- to evaluate the exposure of both private and professional properties to potential but not necessarily occurred natural events, i.e. the stochastic approach.

The financial impact of climate change on a so-called "market" portfolio including all properties currently insured in France has been evaluated using CCR's impact models [4] coupled with climatic projections generated by the ARPEGE-Climat model developed by MétéoFrance [5]. In this paper, we will focus on the two major disasters in terms of historical losses for the Nat Cat compensation scheme: flood and drought.

In this study, floods include flash floods and surface runoff as well as riverine overflow. Droughts represent the swelling and shrinkage of soils rich in clay and its impacts on properties.

This current study highlights the variations of insurance exposure to natural hazards due to climate change.

\footnotetext{
a Corresponding author: $\underline{\text { dmoncoulon@@ccr.fr }}$
} 


\section{Climate change}

\subsection{Overview}

The IPCC has chosen four different scenarios to emphasize future changes in the world's climate [6]. These scenarios are based on the analysis of the variations in greenhouse gas emissions. The median scenario (Relative Concentration Pathways - RCP 4.5), used in the current study, would entail a rise in world temperatures between $1.1^{\circ} \mathrm{C}$ and $2.6^{\circ} \mathrm{C}$ by the end of the $21^{\text {st }}$ century, relative to temperatures in the late- $20^{\text {th }}$ to early-2 $1^{\text {st }}$ centuries (1986-2005 average).

The choice of the scenario is also a key point, we opted for a median scenario (RCP 4.5), envisaging a positive effect of negotiations performed during the COP 21 in late 2015 .

Focusing on France, the last report published by ONERC (Observatoire National sur les Effets du Réchauffement Climatique) $[7,8]$ highlights an increase in temperatures during the $21^{\text {st }}$ century which, in the RCP 4.5 scenario, could reach $+1.6^{\circ} \mathrm{C}$ in winter and $+2.9^{\circ} \mathrm{C}$ in summer at the end of the century.

According to ONERC, this warming could go hand-inhand with an increase in the duration of droughts and heat waves. There would also be more numerous, larger scale extreme rainfall events $[7,8]$.

\subsection{Modelling climate change}

The model developed for estimating the potential impacts of climate change by 2050 is based on MétéoFrance climate modelling, supplying atmospheric data for hazard models developed by CCR.

As part of IPCC activities, Météo-France has implemented its global ARPEGE-Climat [9] model to produce simulations up to 2100 for the whole world. Work is also being done to scale models down to the regional level trough the CORDEX (Coordinated Regional Climate Downscaling Experiment) program.

For CCR's needs, Météo-France configured ARPEGEClimat in order to refine calculations with 31 vertical levels in hourly time increments and with $20 \mathrm{~km}$ resolution in Europe. Two simulations of 200 years were generated with two different constant initial conditions (parameters determining the constant climate such as sea surface temperature and greenhouse gas concentrations):

- one with current climate conditions (year 2000) as the so-called CCO scenario;

- $\quad$ one with future climate conditions (year 2050) as the so-called CC1 scenario.

The CCO simulation set was recalibrated against data from real events which occurred during the last 30 to 40 years.
The hypotheses chosen for computing $\mathrm{CC} 1$ scenario are based on the RCP 4.5 (solar radiation forcing of $+4.5 \mathrm{~W} / \mathrm{m}^{2}$ in 2100) which follows a progression that stabilises without excess by 2100 , with 660 ppm $\mathrm{CO}_{2}$ equivalent, which corresponds to a mean increase of $1.8^{\circ} \mathrm{C}$ in 2100 regarding the current mean temperature.

The choice of the "target" year for the study is fundamentally important. A 35-year leap forward is already a strong hypothesis for these projections, especially for (re)insurance companies, thus the year 2050 was chosen.

The hourly rainfall obtained from these simulations was used to supply CCR impact models for flood. Downscaling to a $8 \times 8 \mathrm{~km}$ grid was performed using a quantile mapping approach on the last 30 years with the climatological database SAFRAN [10].

For drought, Météo-France provided simulation data from the ISBA (Interaction Sol Biosphère Atmosphère) model [11], configured with uniform clay soil content and uniform vegetation type (grass). SWI (Soil Wetness Index), characterising the water content of soils, was produced with daily timesteps.

ISBA simulates exchanges of water and energy between the soil and the atmosphere. The version used has three soil layers (surface, roots area and deep area) and simulates the corresponding temperatures and water. ISBA simulates all flows of water between the surface and 1) the atmosphere (interception, evaporation and transpiration) 2) the ground (surface run-off and drainage in the ground). Its time increment is 5 minutes. ISBAUniforme is configured with a uniform representation of the texture of soils and vegetation in France to clearly identify climate forcing on the whole territory.

\section{Method}

\subsection{Detection of flood events}

A method based on rainfall accumulation has been devised to detect flood events on catchments of different scales, using the rainfall data of the ARPEGE simulations. These events were then simulated with the in-house flood hazard model developed by CCR [1].

The duration used for the rainfall accumulations depends on the size of the catchment: 3-day accumulations were computed for small catchments, and 10-day for large catchments.

The moving annual maximum accumulations (for different durations depending on the catchment size: 3 or 10 days) for each of the 200 simulated years give a distribution of 200 values, the 0.90-quantile of which defines a ten-year threshold, which is therefore different from catchment to catchment and for the two climatic scenarios. 
Using different thresholds for CCO and CC1 means that the definition of extreme events within the French Nat Cat scheme is assumed to evolve continuously with the intensity and frequency of those observed in the future.

The BD CARTHAGE®) (the most complete database of the French hydrographic network [12]) provides information on the boundaries of catchment areas at different scales, the smaller hydrographic basins being nested into the larger ones.

Two different sizes of catchment areas were considered in our study:

- small "hydrographic sectors" subject to significant short rainfalls detected when the 3-day rain accumulation exceeds the ten-year threshold;

- larger "hydrographic regions" used to detect heavier flood-inducing rainfalls on the basis of 10-day rain accumulation above the ten-year threshold.

One large hydrographic region contains up to ten smaller hydrographic sectors in the database.

Moving total rain accumulations were computed for each catchment area on a three-day (or 10-day) period from the 200 simulated years of hourly rainfall data provided by Météo-France and obtained from the ARPEGE-Climat model.

We consider that an event occurs as long as the rainfall accumulation exceeds the threshold. Thus, among continuous climatic data over 200 years, we simulated only the "extreme" events, this could be considered as a semi-continuous modelling method.

The durations of the events on large hydrographic regions being longer, these events are expected to generate extreme floods on the largest rivers.

\subsection{Flood hazard model}

For each flood event, hourly rainfall data is integrated as an input into the in-house surface run-off model and then into the river overflow model developed by CCR [1].

The run-off model calculates the water volumes that flow on the surface and under the surface of the ground, taking into account topography, but also land use, in order to reproduce the behaviour of sealed surface areas.

The river overflow model is used to estimate the flow rate of the main water courses and their overflow during an extreme event. This overflow is based on the spread of water on a digital model of ground, describing the topography of the impacted area.

\subsection{Drought hazard model}

Geotechnical drought - or clay shrinkage-swelling is a hazard caused by climate factors, due to an anomaly in the precipitation. A factor of predisposition has been identified [13]: clay type and its percentage in the soil that may cause ground movements affecting foundations and structures of constructions.

From the daily SWI value computed by Météo-France with the ISBA model, a decadal value of SWI was computed. This temporal resolution is the one used by the governmental commission in charge of deciding whether the effects of a specific drought should be compensated by the French Nat Cat scheme or not.

A drought event is defined by the 36 decadal values of SWI within a single simulated year.

\subsection{Modelling financial loss}

The cost of each event was simulated with the damage model developed at CCR. The simulation was done on an estimated portfolio of the current insurance industry, enabling a direct comparison between the two scenarios.

Having simulated hazard for each peril from climatic and geographical input data, the areas affected by a disaster such as river overflow and surface run-off or geotechnical drought were mapped for each event. In the case of flood, hazard is represented by the level of water $(\mathrm{m})$ in the river flood zone or the surface run-off $\left(\mathrm{m}^{3} / \mathrm{s}\right)$. In the case of drought, the hazard intensity is represented by the 10-day SWI value.

Based on the location of the insured properties and their characteristics, such as the nature of the property (house, building or apartment), the type of risk (private or professional) and its form of occupation (owner-occupier, tenant, joint property owner), and cross-referencing this information with hazard, it is possible to estimate the amount of insured losses.

The damage model takes four factors into account:

- probability that the property will suffer loss,

- associated rate of destruction,

- probability that a natural disaster is officially declared by governmental authorities,

- $\quad$ insured value of the property.

The first three variables are calibrated and calculated in a different way for each peril, on the basis of recent historical events (over the period 1998 - 2013) for which sufficient claim data are available and gathered in CCR's database.

In the end, the estimated costs for each insured item of property are accumulated on different scales: commune, department and the whole France.

\section{Results}

The present analysis will focus on and compare the behaviours of two watersheds as defined in BD CARTHAGE® [12]: 
- "Côtiers Méditerranéens" (hereinafter referenced as $\mathrm{CM}$ ) in the South of France, covering an area of about $40000 \mathrm{~km}^{2}$;

- "Seine-aval-Oise" (hereinafter referenced as $\mathrm{SaO}$ ) in the North of France, covering an area of about $32000 \mathrm{~km}^{2}$.

These two watersheds have been chosen in order to describe the models in two different climatic conditions. These areas exhibit contrasted evolutions related to climate change as they are under influence of different climatic regional conditions: oceanic climate with continental influences (frequent rainfall through the year and mild summer) for the $\mathrm{SaO}$ area and Mediterranean climate (mild winter, dry summer and flash floods in autumn) for the CM area.

The CM watershed has been involved in the major flood events in the last 30 years whereas the $\mathrm{SaO}$ watershed is probably one of the potentially most exposed areas due to the Seine river flooding (i.e. 1910-type event).

\subsection{Hazard}

\subsubsection{Flood}

Each watershed shows an increase of the average annual total rainfall accumulation between $\mathrm{CC} 0$ and $\mathrm{CC} 1$. The increase is more noticeable in the North of France (Table 1 and Figure 1).

\begin{tabular}{|c|c|c|}
\hline & 3-day & 10-day \\
\hline Côtiers Méditerranéens & $2.14 \%$ & $2.17 \%$ \\
Seine-Aval-Oise & $9.44 \%$ & $9.43 \%$ \\
\hline France & $6.14 \%$ & $6.13 \%$ \\
\hline
\end{tabular}

Table 1. Percentage of increase in the average annual rainfall accumulation between the $\mathrm{CC} 0$ and the $\mathrm{CC} 1$ scenarios. The values are similar for 3-day and 10-day accumulations.

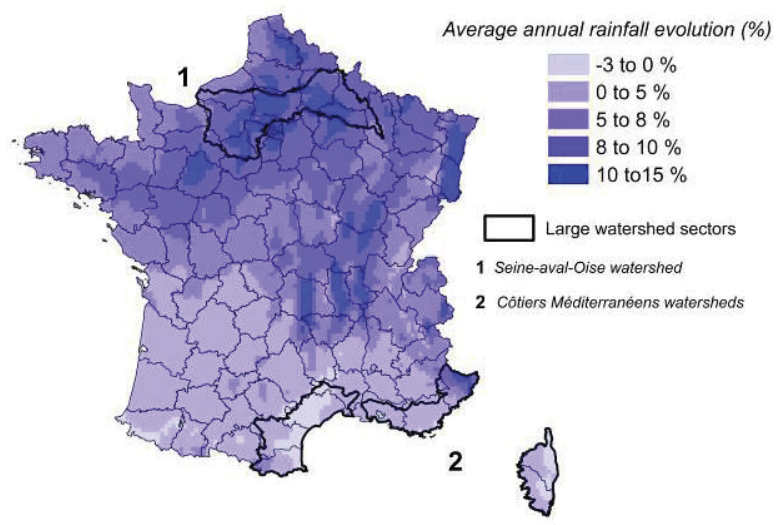

Figure 1. Evolution of the average annual rainfall between the $\mathrm{CC} 0$ and the $\mathrm{CC} 1$ scenarios.

The two watersheds show different behaviours with regard to rainfall and event detection.

To study the dynamic of rainfall throughout the year and across the seasons, we computed the moving rain- accumulation for each day of the year and averaged it over the 200 years of simulation.

In figures 2 and 3 are shown the ratios of variation of these moving averages against the average annual rainfall.

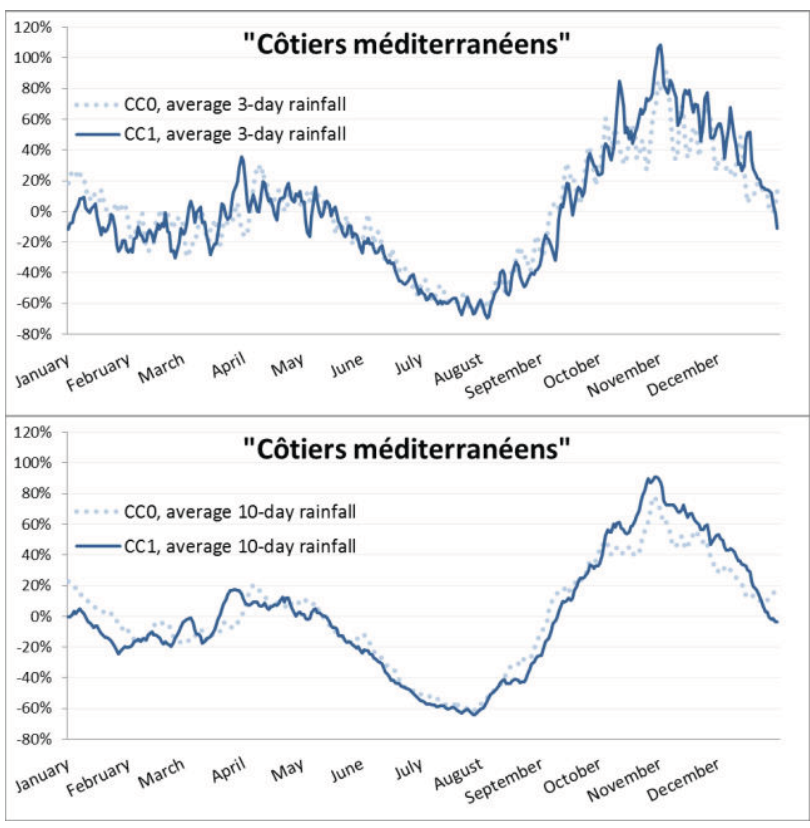

Figure 2. Variation of the moving average rainfall around the average annual rainfall for the "Côtiers Méditerranéens" (CM) watershed.

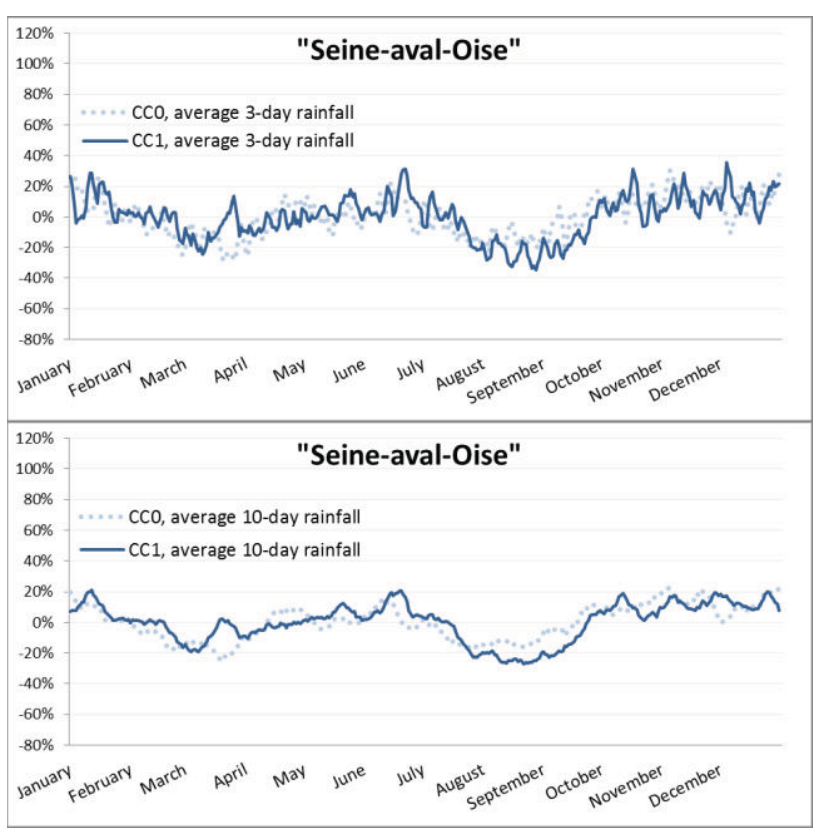

Figure 3. Variation of the moving average rainfall around the average annual rainfall for the "Seine-aval-Oise" $(\mathrm{SaO})$ watershed.

The rainfall on the $\mathrm{CM}$ watershed shows larger variations throughout the year than the $\mathrm{SaO}$ watershed. 
This is also reflected in the detection of events. Events on the CM watershed occur mostly in autumn and winter (from September to January), whereas events on the $\mathrm{SaO}$ watershed occur all throughout the year. This is the case for both climate scenarios (figures 4 and 5). This is consistent with the more numerous flash floods in the South usually occurring at the end of the year.

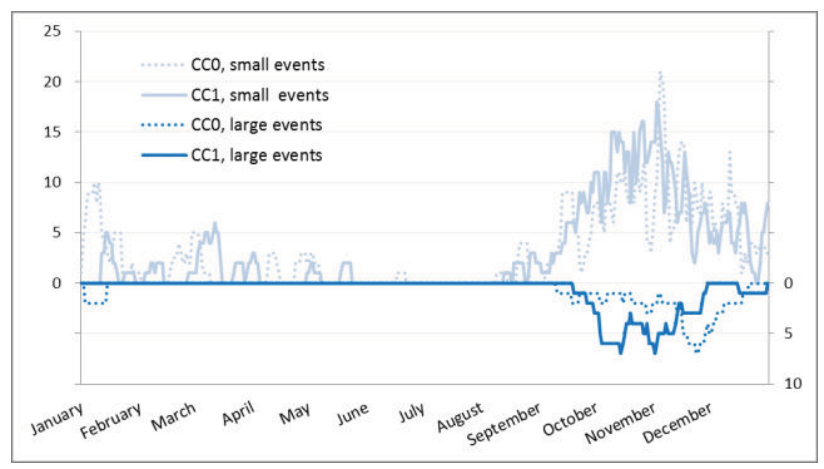

Figure 4. Total number of small and large flood events occurring at different periods of the year for the "Côtiers Méditerranéens" (CM) watershed.

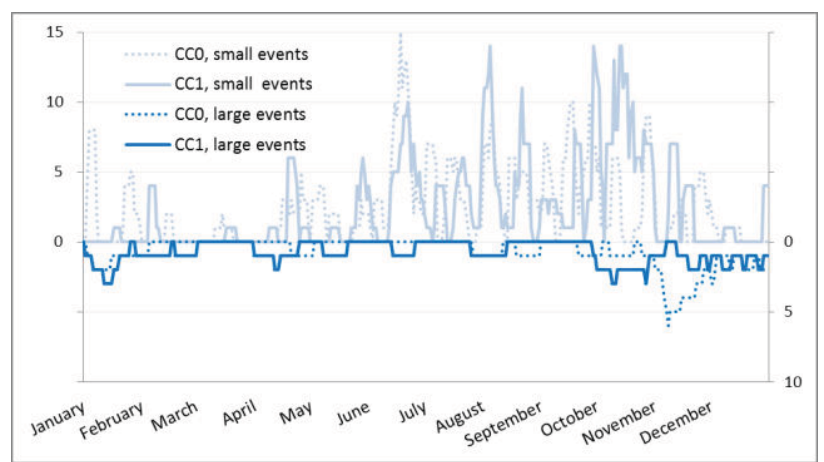

Figure 5. Total number of small and large flood events occurring at different periods of the year for the "Seine-aval-Oise" $(\mathrm{SaO})$ watershed.

\subsubsection{Drought}

The average annual soil moisture variation is illustrated in figure 6 with the current climate simulation set as reference. The modelled data exhibit a strong contrast depending of the region considered.

The north-western part of France tends to be wetter during the whole year whereas the south-eastern part of France would suffer from a severe dryness.

Considering the two regions of interest, the average annual soil moisture variation ranges from $-0.2 \%$ for $\mathrm{SaO}$, meaning that climate change would lead to wetter soils in this area as the precipitations would be more intense (figure 1), while a $+3.5 \%$ is observed on the CM area with extremes dryness up to $+8.1 \%$ locally.

One should also notice that the major mountainous areas would globally suffer from dryness, except the inner Alps. Correlatively, valleys located close to these areas would collect more precipitations leading to a significant hydration (clearly visible in the Rhine valley, the Rhone delta and valleys located in the middle of France).

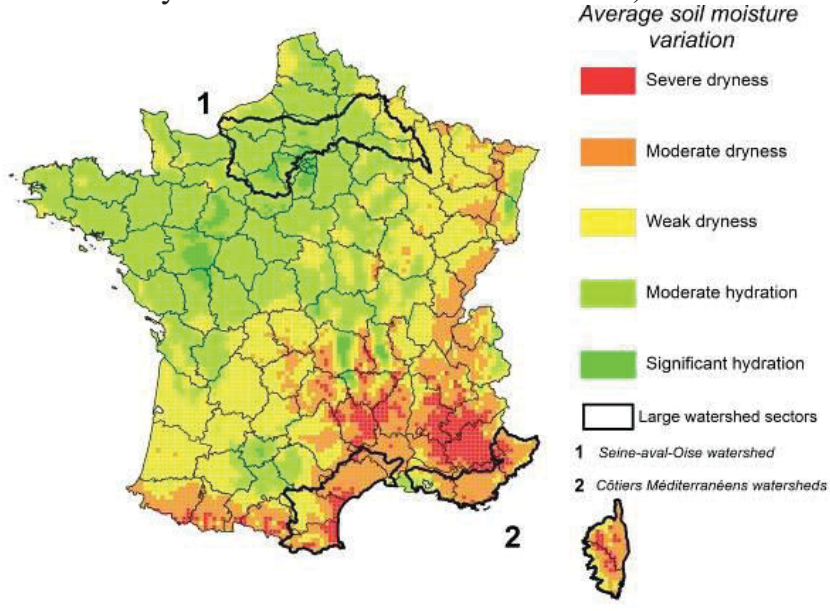

Figure 6. Variation of annually averaged soil wetness related to climate change between today and 2050 .

The decadal evolution of the soil wetness spatially averaged on the extent of $\mathrm{SaO}$ and $\mathrm{CM}$ areas and expressed as a ratio "future climate / current climate" is illustrated on the figure 7 .

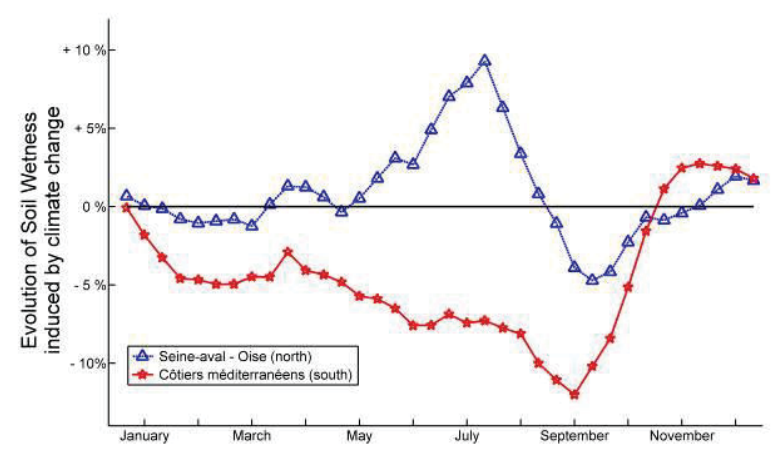

Figure 7. Decadal variation of soil wetness related to climate change between today and 2050 in the northern part of France and near the Mediterranean seashore.

The $\mathrm{SaO}$ area is wetter through the year, especially during summer; a short period of dryness during September is observed, with no more than $5 \%$ dryness. This result is consistent with the 3-day and 10-day average rainfall (figure 3) in $\mathrm{SaO}$. Indeed, rainfall is decreasing in August and September, leading to a significant dryness in September.

In the $\mathrm{CM}$ area, the dryness is severe ranging from 5 to $12 \%$ during half of year. The wetter autumn is also observed in the flood part of this study as the precipitations are significantly increasing in the CM area during autumn. 


\subsection{Damage}

\subsubsection{Flood}

The costs of all events on each watershed, whether based on 3-day ("small events") and on 10-day ("large events") rain accumulation were summed in order to obtain the average annual total cost on the watershed.

The two considered watersheds show an increase in the average total annual cost. The $\mathrm{SaO}$ watershed is a lot more subject to large floods which contribute to a major part (about $60 \%$ ) of the average total annual loss, whereas the CM watershed is mainly subject to small events (Figure 8).

This is not surprising partly because the Rhône river, one of the major rivers of Europe, though nearby, is not included in the CM watershed, which comprises only costal rivers of lesser importance; whereas the Seine river flows in the $\mathrm{SaO}$ watershed.

The CM region is exposed to flash floods characterized by very important rain accumulation during short period of time, essentially due to Mediterranean climate conditions and to important slopes in small coastal watersheds. The $\mathrm{SaO}$ catchments present less marked reliefs and oceanic climatic conditions with longer period of lower rainfall. Rainfall on the $\mathrm{SaO}$ watershed are not as intense all over the year (variation around the mean is smaller) but span a longer period of time, resulting in greater 10-day accumulations and generating large flood events.

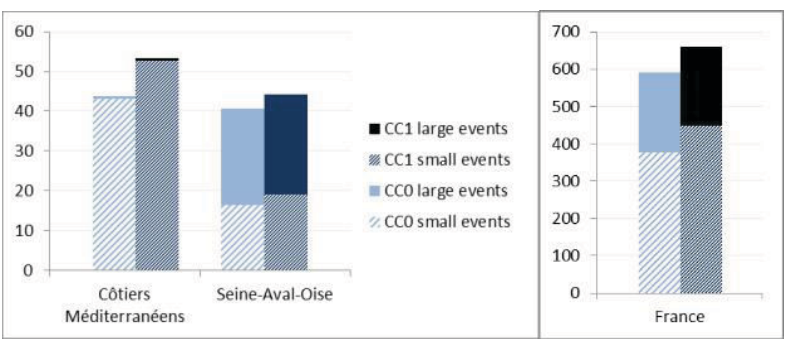

Figure 8. Average annual total cost of floods (in $\mathrm{M} €$ ) for the two watersheds and for France.

A look at higher return periods (30-year return period loss in table 2) shows a more dramatic effect of climate change on the CM watershed compared to the rest of France, but this should be taken with caution considering the number of simulated years used for the study.

\begin{tabular}{|c|c|c|c|}
\hline 30-year return period (M€) & CM & SaO & France \\
\hline CCO (Flood) & 277 & 280 & $\mathbf{2 ~ 2 0 0}$ \\
CC1 (Flood) & 350 & 300 & $\mathbf{2 ~ 4 0 0}$ \\
\hline Effect of climate change (\%) & $+26 \%$ & $+6 \%$ & $+8 \%$ \\
\hline
\end{tabular}

Table 2. Evolution of the 30-year return period loss of floods for Franc and for the "Côtiers Méditerranéens" (CM) and the "Seine-aval-Oise" $(\mathrm{SaO})$ watersheds.

\subsubsection{Drought}

The average annual insured-loss (AAL) from $\mathrm{SaO}$ area shows a variation of $-0.3 \%$ (Table 3 ) which lies largely in the uncertainties of the current study. On the contrary, the AAL in the CM area would increase by $+8.8 \%$ while a moderate increase of $+3.1 \%$ is observed for the whole French mainland. The effect of climate change is clearly heterogeneous considering different areas in France.

\begin{tabular}{l|ccc} 
Average Annual Loss & France & $\begin{array}{c}\text { Seine-aval - Oise } \\
\text { (north) }\end{array}$ & $\begin{array}{c}\text { Côtiers } \\
\text { méditerrannéens } \\
\text { (south) }\end{array}$ \\
\hline Effect of climate change & $+3.1 \%$ & $-0.3 \%$ & $+8.8 \%$
\end{tabular}

Table 3. Evolution on the average annual loss for drought related to climate change for France and the two selected areas showing contrasted regional evolution.

For a long return period of losses, 30 years for instance, the same statements can be addressed (Table 4): the $\mathrm{SaO}$ area shows no significant variation whereas the $\mathrm{CM}$ area would suffer from even dryer drought. A difference can be raised as the losses related to a 30-yr return period are slightly higher than those observed on the average annual basis. Drought tends to be more severe on longer return period with the climate change related to the RCP 4.5 scenario. However this trend needs to be confirmed with additional simulated years as our simulation set contains only 200 simulated years so far.

\begin{tabular}{c|ccc} 
30-yr return period & France & $\begin{array}{c}\text { Seine-aval - Oise } \\
\text { (north) }\end{array}$ & $\begin{array}{c}\text { Côtiers } \\
\text { méditerrannéens } \\
\text { (south) }\end{array}$ \\
\hline Effect of climate change & $+6.8 \%$ & $-0.8 \%$ & $+11.1 \%$
\end{tabular}

Table 4. Evolution on the 30 -year return period loss for drought related to climate change for the whole France and the two selected areas showing contrasted regional evolution.

\subsubsection{Combining the two perils / Global losses}

Most existing natural disaster models are developed for a specific hazard/geographic area. To obtain cumulative results for several hazards, the perils are considered independent; this constitutes a major proxy.

The originality of the current study lays in the use of a unique climatic hazard as an input for both flood and drought impact models with correlated hazards for each simulated year. As a result, the occurrence of events is a response to climatic conditions that are common to the hazards as previously explained.

The results of this study show that climate change would have an impact on the average annual loss experienced with an increase of $7 \%$ due to flood and of $1 \%$ caused by drought for France by 2050 (Fig. 9). 


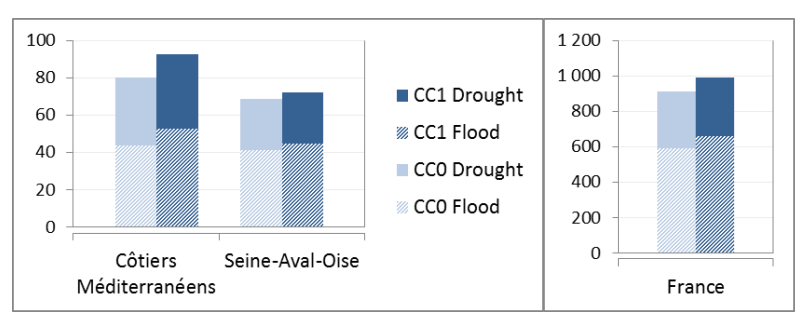

Figure 9. Contributions of flood and drought to the average annual loss (in $\mathrm{M} €$ ).

\section{Discussion}

Coupling the ARPEGE-Climat model from MétéoFrance and the impact models developed by CCR in order to evaluate the financial impact of climate change on the natural disaster scheme on the basis of the IPCC's RCP 4.5 scenario, has led to the identification of the main trends.

From a methodological viewpoint, this study combined an overall large-scale climate model with several models of impacts that operate with very fine spatial resolution.

The simulated number of years remains a preponderant factor of the stability of results. The average annual loss is sensitive to the number of simulated years, but longer return periods (30-year for instance) are more sensitive to extreme values. The duration of computing times and the amount of memory required are the most limiting factors regarding the number of simulated years. Both ARPEGE-Climat and CCR impact models need several weeks of computing.

The model does not take into consideration the variation in preventive measures and the organisation of risk prevention plans in the future. Therefore this study is based on current protection works for the current and future climate conditions.

Considering the whole France, modelled damages are consistent for both the AAL and the 30-yr loss with the losses experienced since the French compensation scheme for natural hazards became effective in 1982. However, at the scale of large watersheds, the same results can only let us rank how costly the watersheds compare. The exact amount of damages at this finer resolution is not expected to be as relevant as the one aggregated on the whole French territory.

The analysis of correlated damage is difficult to assess. Indeed, for flood, all the properties (residential, commercial and industrial lines of business) are included in the model whereas for drought the model only considers the impact on individual dwellings (houses). Furthermore, for commercial and industrial properties, the insurance coverage is extended to business interruption which tends to weigh more in the total cost as the severity of flood increases; this component of losses does not exist for the drought impact model.

\section{Perspectives}

For this study, we chose the IPCC's RCP 4.5 scenario as it seemed consistent with the goals of the COP 21 conference (2015) prior to its completion.

In order to have alternate and plausible insights into climate change by 2050 , we will perform new simulation using the RCP 8.5 scenario, the most pessimistic of the IPCC's scenarios established to date.

Larger datasets of 400 simulated years are expected to be later generated in order to refine our assessment of the impact of climate change for the French insured properties for both the RCP 4.5 and RCP 8.5 scenarios.

A stochastic approach based on the turning band method [14] could be one way to generate as many sequences of rainfall data as desired, addressing the issue that to given climatic conditions at large resolution corresponds an infinity of potential downscaled rain fields.

Finally, the French offshore territories, located mainly in the West Indies and in the Indian Ocean, are also intended to be incorporated in the scope of our study, for flood, storm surge and cyclonic winds.

\section{References}

1. Moncoulon, D., Labat, D., Ardon, J., Leblois, E., Onfroy, T., Poulard, C., Aji, S., Rémy, A., Quantin, A. (2014). Analysis of the French insurance market exposure to floods: a stochastic model combining river overflow and surface runoff. Natural Hazards and Earth System Science 14, 2469-2485

2. Quantin, A., Ardon, J., Tinard, P. (2015), Probabilistic modelling of drought hazard within the French natural Catastrophe Compensation Scheme. International Symposium - Shrink-swell processes in soils - Climate and constructions, Eds IFSTTAR.

3. Naulin, J.-P., Moncoulon, D., Le Roy, S., Pedreros, R., Idier, D., Oliveros, C. (2016). Estimation of insurance-related losses resulting from coastal flooding in France, Natural Hazards and Earth System Science 16

4. CCR (2015). Impacts financiers du changement climatique sur le régime d'indemnisation des Catastrophes Naturelles à horizon 2050, http://www.ccr.fr/blobs/com.cardiweb.cardiboxv6.c m.business.Article/3183220364951949283/document Joint/1/etude \%20climat.pdf

5. Déqué, M., Dreveton, C., Braun, A., Cariolle, D. (1994). The ARPEGE-IFS atmosphere model: A contribution to the French community climate modelling. Climate Dynamics 10 : 249-266

6. IPCC Climate Change (2013). The Physical Science Basis. Contribution of Working Group I to the Fifth Assessment Report of the Intergovernmental Panel on Climate Change [Stocker, T.F., D. Qin, G.-K. Plattner, M. Tignor, S.K. Allen, J. Boschung, A. Nauels, Y. Xia, V. Bex and P.M. Midgley (eds.)]. 
Cambridge University Press, Cambridge, United Kingdom and New York, NY, USA

7. ONERC (2014). Le climat de la France, Volume 4. Scénarios régionalisés: Edition 2014 la métropole et les régions d'Outre-Mer

8. ONERC (2015). Le climat de la France, Volume 5. Changement climatique et niveau de la mer: de la planète aux côtes françaises

9. Déqué, M., (2010): Regional climate simulation with a mosaic of RCMs. Meteorologische Zeitschrift 19: 259-266, doi : 10.1127/0941-2948/2010/0455.

10. Vidal, J.-P., Martin, E., Franchistéguy, L., Baillon, M. and Soubeyroux, J.-M. (2010), A 50-year highresolution atmospheric reanalysis over France with the Safran system. International Journal of Climatology, 30 : 1627-1644. doi : 10.1002/joc.2003

11. Noilhan, J. and J.-F. Mahfouf (1996). The ISBA land surface parameterization scheme. Global and Planetary Change, 13, 145-159.

12. IGN (2006), BD CARTHAGE® v. 3.0 - Descriptif de contenu, http://www.sandre.eaufrance.fr/sites/default/files/IM G/pdf/1-DC_BDCARTHAGE_3_0.pdf

13. Geremev, Z., Audiguier., M., Cojean., R. (2009). Analyse du comportement d'un sol argileux sous sollicitations hydriques cycliques. Bull. Eng. Geol. Environ., 421-436

14. Leblois, E., Creutin, J.-D. (2013). Space-time simulation of intermittent rainfall with prescribed advection field: adaptation of the turning band method, Water Ressour. Res., 49, 3375-3387. 